\title{
Improvement of Femoral Bone Quality After Low-Magnitude, High-Frequency Mechanical Stimulation in the Ovariectomized Rat as an Osteopenia Model
}

\author{
M. Tezval $\cdot$ M. Biblis $\cdot$ S. Sehmisch $\cdot$ \\ U. Schmelz • L. Kolios • T. Rack • K. M. Stuermer • \\ E. K. Stuermer
}

Received: 9 January 2010/Accepted: 19 January 2010/Published online: 31 October 2010

(C) The Author(s) 2010. This article is published with open access at Springerlink.com

\begin{abstract}
The treatment and prevention of osteoporosis involve great challenges. Nonpharmacological and supportive therapy procedures, sport, and physical exercises seem to prevent bone loss and improve bone mass. In the present study, we examined the effect of whole-body vertical vibration (WBVV) on femoral intertrochanteric bone quality in the rat osteoporosis model. Sixty female Sprague-Dawley rats, 3-month old, were ovariectomized (OVX) or sham-operated. After 3 months, each group was divided into two subgroups. In one of the subgroups, rats were treated with WBVV at $90 \mathrm{~Hz}(3.9 \mathrm{~g})$ for 35 days; the second subgroup remained untreated. After killing the
\end{abstract}

The authors have no conflict of interest.

M. Tezval $(\bowtie) \cdot$ M. Biblis · S. Sehmisch · L. Kolios ·

T. Rack - K. M. Stuermer · E. K. Stuermer

Department of Trauma and Reconstructive Surgery, Georg-

August-University of Goettingen, Robert Koch Str. No. 40,

37075 Goettingen, Germany

e-mail: mtezval@med.uni-goettingen.de

S. Sehmisch

e-mail: stephan.sehmisch@med.uni-goettingen.de

L. Kolios

e-mail: leilakolios@freenet.de

T. Rack

e-mail: track@gwdg.de

K. M. Stuermer

e-mail: km.stuermer@med.uni-goettingen.de

E. K. Stuermer

e-mail: e.stuermer@med.uni-goettingen.de

U. Schmelz

Medical Institute of General Hygiene and Environmental Health,

University of Goettingen, Goettingen, Germany

e-mail: ullischmelz@aol.com animals, biomechanical strength and trabecular bone architecture of the proximal region of femurs were analyzed. New cortical bone appositions and mineral density of femurs were additionally measured. Treatment with WBVV resulted in improved biomechanical properties. Maximal load and stiffness of the intertrochanteric region of femurs after WBVV were significantly enhanced. Maximal load and stiffness in treated OVX animals reached the levels observed in untreated sham rats. WBVV significantly improved all measured histomorphometric parameters in the trabecular area. Treated rats showed significantly improved mineral content in ashed femurs compared to untreated animals. A comparison of widths of fluorescence bands in cortical bone of subtrochanteric cross sections did not show any significant differences between the groups after WBVV. Low-magnitude, high-frequency mechanical stimulation improves bone strength in the proximal femur and may be a possible nonpharmacologic treatment option for postmenopausal osteoporosis.

Keywords Osteoporosis - Whole-body vertical vibration $\cdot$ Rat femur $\cdot$ Mechanical stimulation

Postmenopausal osteoporosis, its prophylaxis and therapy, are still challenges; and this has become an increasingly important public health issue [1]. The undesired side effects of long-term estrogen-replacement therapy have already led researchers to look for other pharmacological and nonpharmacological alternatives. Current treatment of osteoporosis is largely dependent on drugs. However, the drugs have certain side effects with long-term use, which is a reason that some patients refuse such medications [1]. In addition to the antiosteoporotic drugs, nonpharmacological procedures, like physical exercise, coordination training, 
and fall prevention, have gained importance in the treatment of osteoporosis over recent years.

Mechanical loading is known to be an effective stimulation factor of bone formation [2], although the exact mechanism is unknown. It was recently reported that whole-body vibration can be osteogenic and, therefore, may represent a noninvasive supportive alternative for the treatment of osteoporosis [3, 4].

The ovariectomized (OVX) rat is a validated experimental model of postmenopausal osteoporosis that develops substantial osteoporosis a few months after OVX [5].

Fracture of the human proximal femur is one of the most frequent fracture types observed in the osteoporotic skeleton. The proximal part of the rat femur shows great similarity with that of the human femur. Because of many similarities between human and rat bone (cellular and tissue levels, trabecular bone, endocortical envelope, etc.), the rat proximal femur is as good as any other routinely used nonhuman skeletal site for measuring bone morphometric changes [6].

In the present study, we demonstrate the effects of whole-body vertical vibration (WBVV) on bone quality of the proximal femur in the rat osteoporosis model.

\section{Materials and Methods}

\section{Animals and Vibration Procedure}

All procedures were reviewed and approved by the Institutional Animal Care and Use Committee (Braunschweig, Germany; AZ 509.42502/01-53.03).

Sixty female Sprague-Dawley (Fa. Winkelmann, Borken, Germany) rats underwent OVX or sham operation ( $n=30$ in each group) at the age of 3 months. All animals were housed in individual cages and allowed free access to standard rodent chow and water. Animals remained untreated for 3 months to allow for the development of osteoporosis. At this point, bilateral osteotomy and osteosynthesis of tibias were performed. Fifteen rats from the OVX group and 15 rats from the sham group were placed on a vibration platform two times a day, for 15 min each time, 7 days a week. Animals were treated for 35 days. The vibration motor was constructed as a cement shaker (Vibra Drehstorm-Vibrationsmotor Typ HVL/HVE; Schultheis, Offenbach, Germany). Rats were allowed to move freely in the cage during vibration. The vibration motor worked at a frequency of $90 \mathrm{~Hz}$, with an acceleration of $3.9 \mathrm{~g}$ (amplitude $0.5 \mathrm{~mm})$. The rest of the rats from each group $(n=15$ for OVX and $n=15$ for sham) remained untreated. After killing the animals, both femurs were cleaned of skin, muscle, and tendons and stored in tubes at $-20^{\circ} \mathrm{C}$ until analysis.
Our study aimed to analyze the effect of WBVV on both osteotomized and intact osteoporotic rat bone. The experiment presented in our study focuses mainly on the effects of WBVV on intact proximal femur, one of the most important skeletal sites in osteoporosis research. Tibial osteotomy presents a model for fracture healing and will be presented separately in the near future.

\section{Biomechanical Test}

Our breaking test was designed to produce trochanteric fractures as previously described [7]. A 4-mm deepening on the proximal side fixed the femoral head. On the other side, the femur was able to move freely between two movable rolling cylinders. A Zwick testing machine (type 145660 Z020/TND; Zwick/Roell, Ulm, Germany) applied the force (Fig. 1).

During the breaking test, actual strength was recorded every $0.1 \mathrm{~mm}$ during the lowering of the stamp. The testXpert software (Zwick/Roell, Germany) continuously recorded the force applied until total failure of the bone occurred. After the failure, the software program indicated
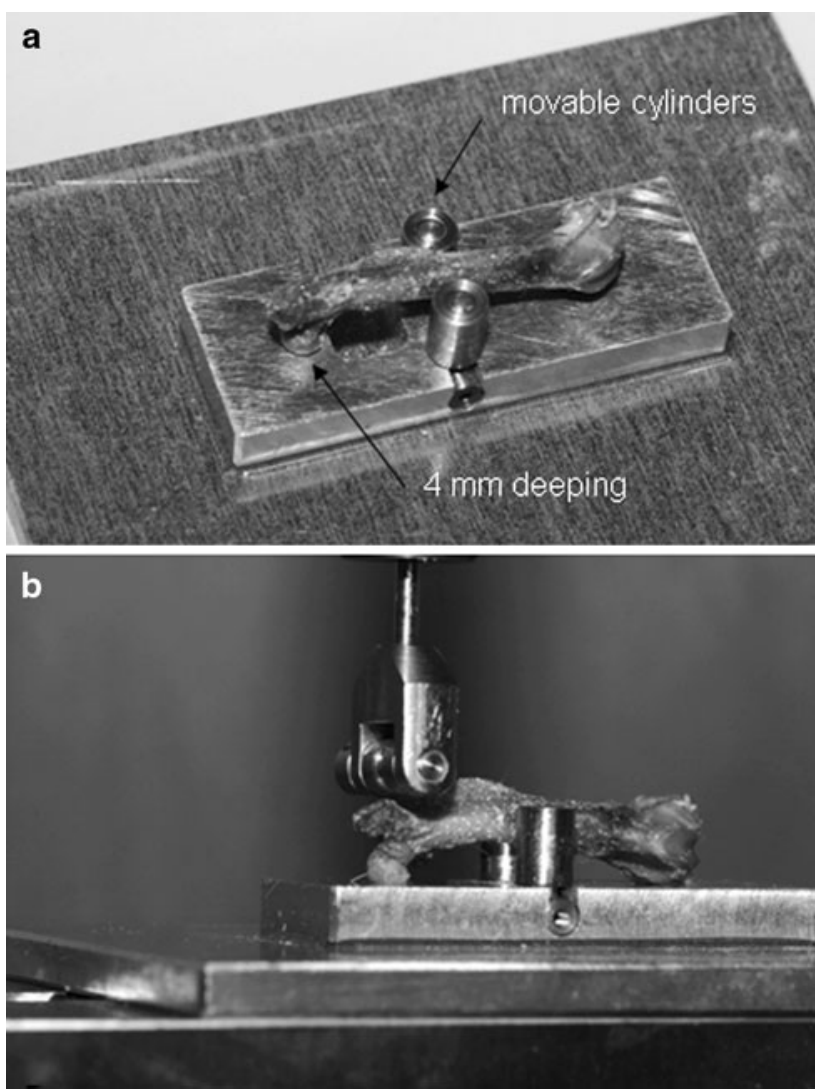

Fig. 1 a The breaking test was designed to produce trochanteric fractures [7]. A 4-mm deepening on the proximal end fixed the femoral head. On the distal side, the femur was able to move freely between two movable rolling cylinders. b A Zwick testing machine (type 145660 Z020/TND, Zwick/Roell) applied the force 


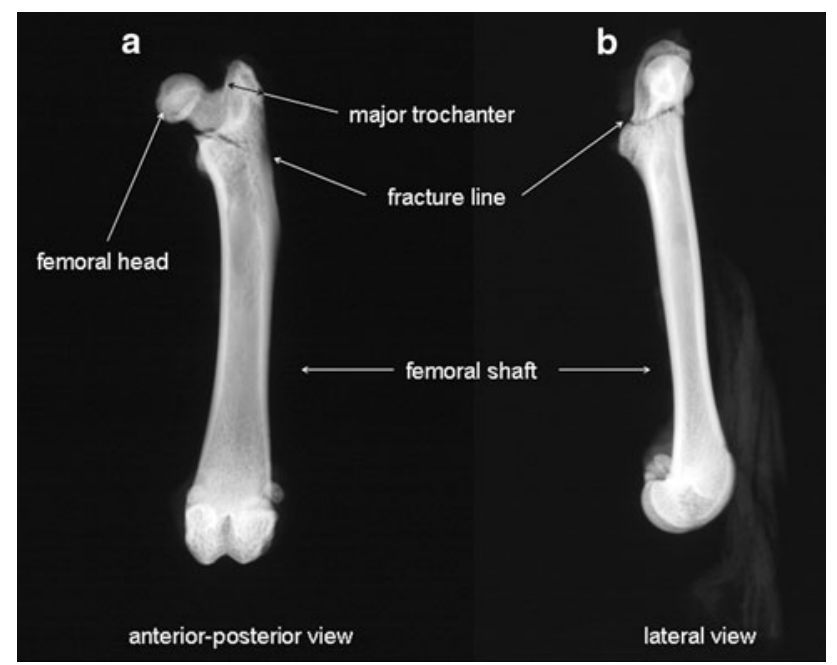

Fig. 2 Radiographs of the left femur of a Sprague-Dawley rat after the breaking test. Our breaking machine is able to produce reverse trochanteric fractures of the femurs (type $\mathrm{A}_{3}$ according to $\mathrm{AO}$ classification). a Anterior-posterior view. b Lateral view

the maximum load $\left(F_{\max }\right)$ and the breaking strength. $F_{\max }$ is the highest force that the femur can withstand [7]. Stiffness was calculated according to the method described in Stuermer et al. [8].

\section{X-Ray Examination of Fractures}

Radiographs in the anterior-posterior and lateral views were taken of all femurs tested in the study. A special film (SR type 45; Kodak, Rochester, NY) and a Faxitron fine-focus cabinet X-ray system (model 43855A; Faxitron $\mathrm{X}$-ray System, Wheeling, IL) with $40 \mathrm{kV}$ were used (Fig. 2).

\section{Histomorphometric Analysis of Cancellous Bone}

Structure

Undecalcified femurs were dissected and cleaned of soft tissues, fixed in $70 \%$ ethanol for $48 \mathrm{~h}$, dehydrated, and embedded in methylmethacrylate. Sagittal sections (150 $\mu \mathrm{m}$ thick) through the proximal femur were cut with a microtome (Sägemikrotom 1600; Leica, Nussloch, Germany). The region of interest for the histomorphometric test was a frame where the proximal part of the femur included the neck and intertrochanteric region. Microradiographs of sagittal sections were used to measure structural changes in the trabecular bone areas.

A digitizing morphometric system was used to measure histomorphometric parameters. The system consisted of a microscope (Leica-System MZ 7.5), a digitizing pad coupled to a PC, and a morphometry program (Qwin software, Leica).
The epiphysis line of the capitis femoris represented the proximal border of the histomorphometric frame. The distal limit of the sections was marked by the base of the major trochanter. We assessed the ratio of trabecular bone area to total cancellous bone area at the proximal femur (Tb.Ar), trabecular connectivity $\left(\mathrm{N} . \mathrm{Nd} / \mathrm{mm}^{2}\right)$, and trabecular thickness (Tb.Wi).

\section{Intravital Fluorochrome Labeling}

During the drug treatment (35 days), animals were subcutaneously injected with four fluorescent markers (Merck, Darmstadt, Germany) to label the process of bone formation and restoration. The fluorochromes used were xylenol orange $(90 \mathrm{mg} / \mathrm{kg})$ on day 13 , calcein green $(10 \mathrm{mg} / \mathrm{kg})$ on day 18 , alizarin red $(30 \mathrm{mg} / \mathrm{kg})$ on day 24 , and tetracycline $(25 \mathrm{mg} / \mathrm{kg})$ on day 35 . The main aims of fluorescence analysis were the (quantitative) evaluation of changes and especially the localization of bone formation in the cortical region. New bone formation in these cross sections can appear at periosteal and/or endosteal sites, with differences under various therapeutic options and conditions.

The results of fluorochrome labeling were analyzed quantitatively for cortical surface in the subtrochanteric region of the femurs $15 \mathrm{~mm}$ distal from the femoral head. The average width of the fluorescence apposition bands was assessed in the ventrolateral quadrant of the cross sections (because of thick muscle cuff and prominent muscle insertion in this area with significant cortical bone response on mechanical stimulation) at a microscopic magnification level of $400 \times$ at both the periosteal and endosteal sites [7].

In addition, we evaluated (qualitatively) differences in the intensity of fluorescent appositions in the trabecular area in the sagittal sections of proximal femurs.

\section{Ashing}

In order to determine the amount of mineralized bone, after the breaking test, the left femurs were mineralized at $750^{\circ} \mathrm{C}$ and weighed to the nearest $0.00001 \mathrm{~g}$. Femurs were weighed before and after ashing. We measured the ratio between the femoral weights before and after ashing and presented the data as percentages.

\section{Evaluation and Statistics}

The results were analyzed using a two-way analysis of variance (ANOVA) (Prism; GraphPad, San Diego, CA). Two parameters, influence of OVX and effect of vibration, were assessed using that test. 


\section{Results}

Fracture Classification

We produced reverse trochanteric fractures of the femurs (type $\mathrm{A}_{3}$ according to the $\mathrm{AO}$ classification). All of these fractures showed great similarity in the localization and type of fractures. We observed in few cases a tilt of the femurs during the biomechanical test due to an inaccurate breaking curve. These cases were not taken into consideration. Here, we present data only from femoral trochanteric fractures as previously described [7] (Fig. 2).

\section{Body Weight}

At the beginning of the study, the body weights of animals did not show any significant differences (Table 1). The sham-operated animals gained significantly less weight ( $\Delta$ weight gain sham $=75.4 \mathrm{~g}, \Delta$ weight gain sham$\mathrm{vib}=75.2 \mathrm{~g}$ ) than $\mathrm{OVX}$ rats $(\Delta$ weight gain $\mathrm{OVX}=$ $142.5 \mathrm{~g}, \Delta$ weight gain OVX-vib $=130.3 \mathrm{~g})(P<0.05)$. The vibrated animals in the OVX group gained less weight than the nonvibrated animals, but the differences were statistically not significant.

\section{Breaking Strength After Whole-Body Vibration}

Biomechanical changes were examined after low-magnitude, high-frequency mechanical stimulation of left femurs. The mean values of the biomechanical parameters $F_{\max }$ and stiffness were significantly higher in OVX-vib rats
$\left(F_{\max }=166.1 \mathrm{~N}\right.$, stiffness $\left.=326.1 \mathrm{~N} / \mathrm{mm}\right)$ compared to the OVX (nonvib) $\left(F_{\max }=147.8 \mathrm{~N}\right.$, stiffness $=245.9 \mathrm{~N} /$ $\mathrm{mm}$ ). The biomechanical parameters were also significantly higher in the sham-operated animals after vibration (sham nonvib $F_{\max }=164.8 \mathrm{~N}$, stiffness $=326.6 \mathrm{~N} / \mathrm{mm}$ vs. sham vib $F_{\max }=181.2 \mathrm{~N}$, stiffness $\left.=355.4 \mathrm{~N} / \mathrm{mm}\right)($ Table 1$)$.

Histomorphometric Changes in the Proximal Femur After Whole-Body Vibration

The results of the histomorphometric analysis and microarchitectural parameters are summarized in Table 1.

Sham-operated animals demonstrated a significantly greater increase of the measured parameters in histomorphometric evaluation compared to OVX rats. Treatment with low-magnitude, high-frequency vibration induced a significant improvement of all tested morphologic parameters. Vibration resulted in significant increases in trabecular bone area $(P<0.05)$, trabecular width $(P<0.05)$, and connectivity $(P<0.05)$ (Table 1$)$.

\section{Mineral Content After Ashing}

The mineral content of femurs was measured after ashing in all groups. The mineral content in sham rats was significantly improved compared to OVX animals $(P<0.05)$; after ashing, the sham-operated femurs had higher ash weights compared to OVX femurs. Vibration yielded a significant improvement of ash mineral content in femurs of all treated groups $(P<0.05)$ (Table 1$)$.

Table 1 Results of the study

\begin{tabular}{|c|c|c|c|c|c|c|c|c|c|c|}
\hline & \multicolumn{2}{|l|}{ OVX } & \multicolumn{2}{|c|}{ OVX Vib } & \multicolumn{2}{|l|}{ Sham } & \multicolumn{2}{|c|}{ Sham Vib } & \multirow{2}{*}{$\begin{array}{l}\text { OVX vs. sham } \\
P\end{array}$} & \multirow{2}{*}{$\begin{array}{l}\text { Vib vs. nonvib } \\
\text { (both OVX and } \\
\text { sham groups) } \\
P\end{array}$} \\
\hline & Mean & SD & Mean & SD & Mean & SD & Mean & SD & & \\
\hline \multicolumn{11}{|l|}{ Body weight (g) } \\
\hline Before OVX & 228.6 & 10.4 & 225.2 & 9.4 & 227.0 & 8.3 & 223.1 & 8.0 & $>0.05$ & $>0.05$ \\
\hline At the end of trial & 371.1 & 40.8 & 355.5 & 34.7 & 302.4 & 20.9 & 298.3 & 22.3 & $<0.05$ & $>0.05$ \\
\hline \multicolumn{11}{|l|}{ Biomechanical test } \\
\hline$F_{\max }(\mathrm{N})$ & 147.8 & 20.79 & 166.1 & 21.30 & 164.8 & 33.83 & 181.2 & 21.20 & $<0.05$ & $<0.05$ \\
\hline Stiffness (N/mm) & 245.9 & 32.76 & 326.1 & 67.53 & 326.6 & 80.76 & 355.4 & 92.30 & $<0.05$ & $<0.05$ \\
\hline \multicolumn{11}{|l|}{ Histomorphometry } \\
\hline Connectivity (N.Nd/mm²) & 14.53 & 2.80 & 19.59 & 2.244 & 26.84 & 6.136 & 28.52 & 4.961 & $<0.05$ & $<0.05$ \\
\hline Trabecular area $(\%)$ & 48.88 & 9.102 & 60.63 & 9.528 & 70.02 & 10.27 & 79.62 & 7.825 & $<0.05$ & $<0.05$ \\
\hline Trabecular width $(\mathrm{mcm})$ & 10.97 & 1.322 & 11.93 & 1.772 & 11.93 & 1.564 & 12.89 & 1.953 & $<0.05$ & $<0.05$ \\
\hline $\begin{array}{l}\text { Mineral content (after ashing) } \\
\text { in left femurs }(\%)\end{array}$ & 43.16 & 1.902 & 46.41 & 2.885 & 46.34 & 2.497 & 46.71 & 3.404 & $<0.05$ & $<0.05$ \\
\hline
\end{tabular}

The $P$ value of the difference between treated and untreated animals was calculated using a two-way ANOVA. $P<0.05$ was considered significant. There are no interactions between OVX and vibration (Vib) 

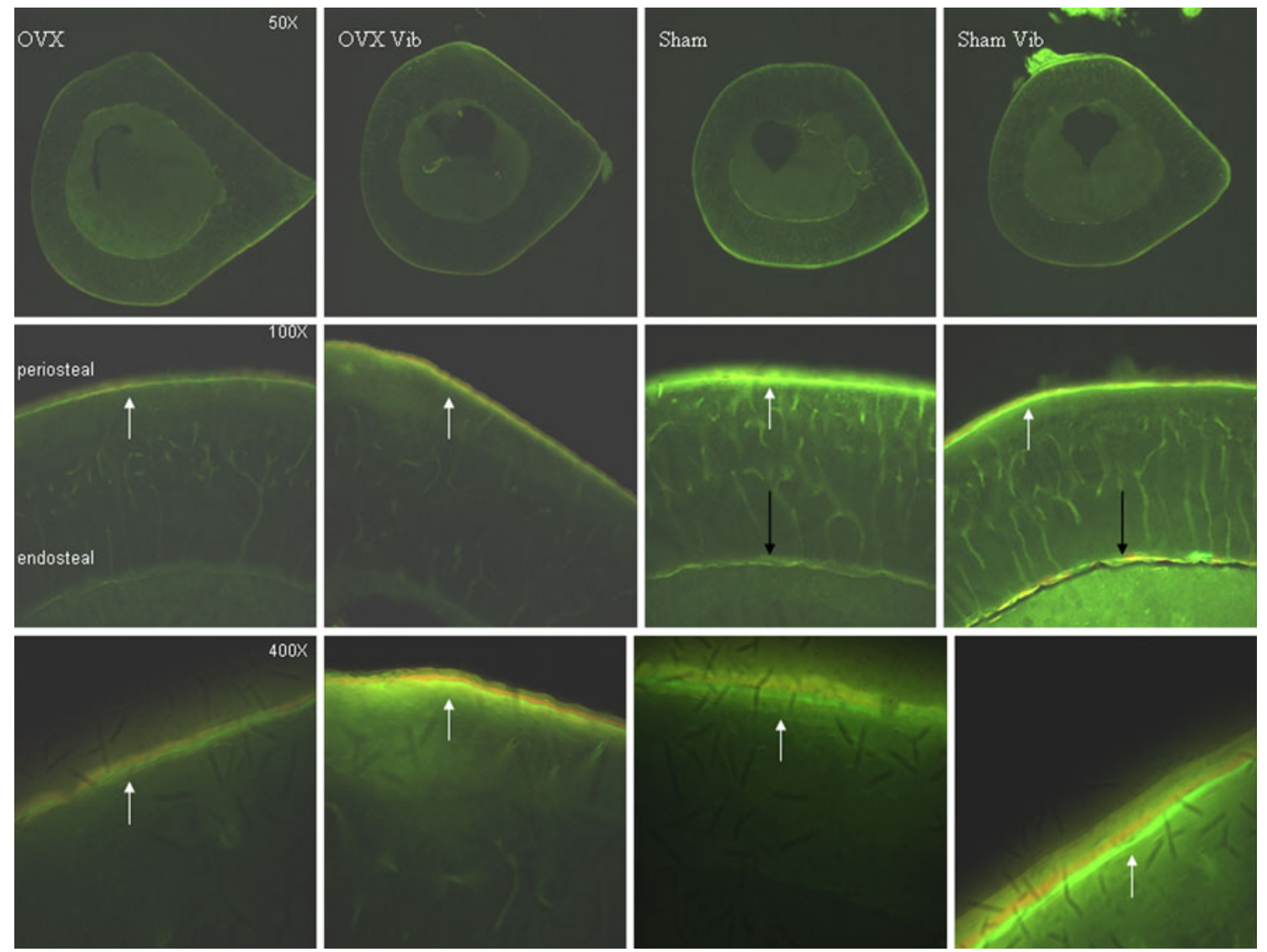

Fig. 3 Bone-formation activity (three magnification levels: 50×, $100 \times$, and $400 \times)$ in cross sections of the subtrochanteric region (15 mm distal to the head) of rat femurs (fluorescence apposition bands in the trochanter tertius). Apposition bands are mainly seen at

the periosteal site (white arrows) in all groups. Only in the sham groups (both vibrated and nonvibrated) did we observe moderate endosteal apposition (black arrows)

\section{Analysis of Fluorescence Apposition Bands}

We measured the fluorescence bands in both periosteal and endosteal sides of the cortex in cross sections cut $15 \mathrm{~mm}$ distal to the femoral head. For this measurement we used a digital imaging system. Because of the low color intensity of the xylenol orange (XO) bands and related overlabeling by calcein green (CG), we were able to measure only apposition bands marked by the red (alizarin red [AK]), light green (CG and $\mathrm{XO}$ ), and yellow (tetracycline [TC]) labels. Figure 3 presents the different apposition bands, and Table 2 shows the quantitative analysis of bandwidth. WBVV seemed to have an influence on the perisoteal side of the cortex in both the OVX and sham groups, but the results were not statistically significant. The vibration (in both OVX and sham groups) did not show any significant changes on the endosteal surface. In contrast to sham animals, OVX rats showed no significant reactions on the endosteal side.

The changes in trabecular area of the proximal femur in the sagittal sections showed an increase of intensity of fluorescent appositions (Fig. 4). This evaluation, however,

was only a qualitative observation (not a quantitative analysis).

\section{Discussion}

Over recent years, mechanical stimulation of bone has garnered more attention in the fields of bone science, sports medicine, and rehabilitation research [2,9]. Mechanical vibration is one of the forms of mechanical stimulation [2]. There is growing evidence that extremely small mechanical signals, if applied at a sufficiently high frequency, can serve as anabolic signals to bone tissue [10].

Information regarding the short-term effects of WBVV on the trochanteric region of the femur in animal models is rare [11]. Femoral intertrochanteric fracture is one of the most common fracture types in humans, especially in patients with progressive osteoporosis. This part of the femur contains both trabecular and cortical bone, in contrast to the femoral shaft (lack of trabecular bone) [7]. The proximal part of the rat femur therefore seems to be an important area in which to investigate the biomechanical 
Table 2 Results from intravital fluochrome labeling

\begin{tabular}{|c|c|c|c|c|c|c|c|c|c|c|}
\hline & \multicolumn{2}{|l|}{ OVX } & \multicolumn{2}{|c|}{ OVX Vib } & \multicolumn{2}{|l|}{ Sham } & \multicolumn{2}{|c|}{ Sham Vib } & \multirow{2}{*}{$\begin{array}{l}\text { OVX vs. } \\
\text { sham } \\
P\end{array}$} & \multirow{2}{*}{$\begin{array}{l}\text { Vib vs. nonvib } \\
\text { (both OVX and } \\
\text { sham groups) } \\
P\end{array}$} \\
\hline & Mean & SD & Mean & SD & Mean & SD & Mean & SD & & \\
\hline \multicolumn{11}{|l|}{ Periosteal apposition } \\
\hline \multicolumn{11}{|c|}{ Absolute apposition bandwidth (mcm) } \\
\hline Calcein green $(\mathrm{d} 0-\mathrm{d} 18)$ & 9.49 & 2.33 & 10.26 & 4.29 & 8.65 & 1.26 & 8.77 & 2.08 & $>0.05$ & $>0.05$ \\
\hline Alizarin red (d18-d24) & 9.43 & 3.20 & 8.63 & 2.17 & 8.67 & 1.24 & 7.22 & 2.22 & $>0.05$ & $>0.05$ \\
\hline Tetracycline (d24-d35) & 13.51 & 5.28 & 14.84 & 3.79 & 13.15 & 2.21 & 14.27 & 3.77 & $>0.05$ & $>0.05$ \\
\hline Sum & 32.43 & & 33.73 & & 30.47 & & 30.26 & & & \\
\hline \multicolumn{11}{|l|}{ Endosteal apposition } \\
\hline \multicolumn{11}{|c|}{ Absolute apposition bandwidth (mcm) } \\
\hline Calcein green $(\mathrm{d} 0-\mathrm{d} 18)$ & \multirow{4}{*}{\multicolumn{2}{|c|}{ No significant appositions }} & \multirow{4}{*}{\multicolumn{2}{|c|}{ No significant appositions }} & 3.91 & 1.46 & 3.91 & 1.3 & $<0.05$ & $>0.05$ \\
\hline Alizarin red (d18-d24) & & & & & 3.93 & 1.055 & 4.11 & 1.32 & $<0.05$ & $>0.05$ \\
\hline Tetracycline (d24-d35) & & & & & 3.97 & 1.47 & 3.54 & 1.48 & $<0.05$ & $>0.05$ \\
\hline Sum & & & & & 11.81 & & 11.56 & & & \\
\hline
\end{tabular}

The widths of apposition bands, calcein green, alizarin red, and tetracycline in cortical surface in subtrochanteric cross sections of rat femurs (15 mm distal from femoral head) were measured by fluorescence microscopy $(400 \times)$. The $P$ value of the difference between treated and untreated animals was calculated using a two-way ANOVA. $P<0.05$ was considered significant. There are no interactions between OVX and vibration (Vib)
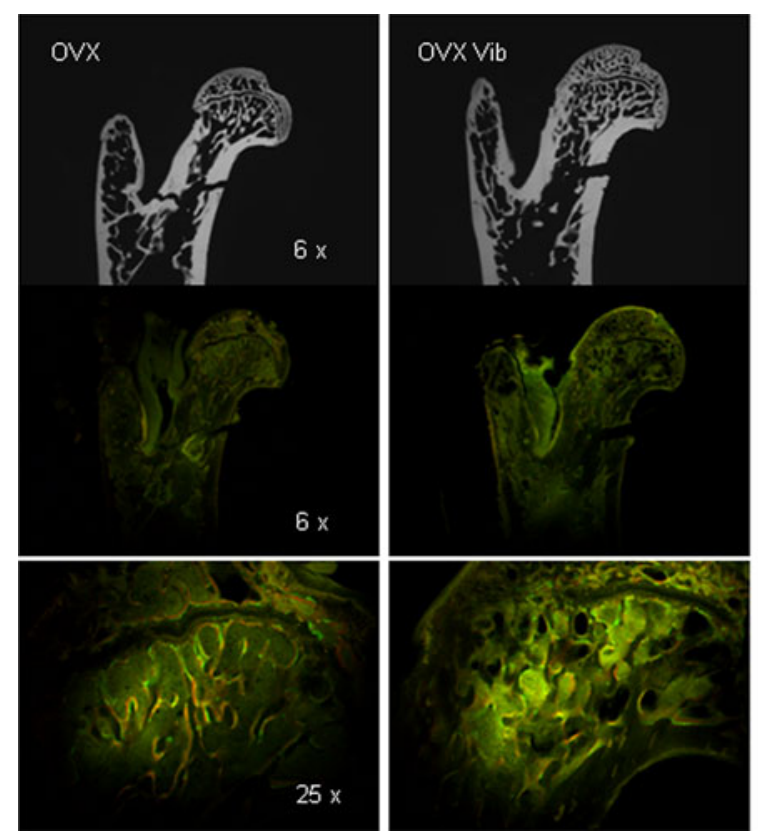

Fig. 4 Upper row Microradiographs of proximal femurs of SpragueDawley rats after breaking test $(6 \times)$. Please note the higher content of trabeculae in both the OVX-vib and sham-vib groups. Middle row Fluorescence microscopy of the same femurs (from upper row) under $6 \times$ magnification. Lower row Magnification $(25 \times)$ of the femoral sections of the same femurs (upper and middle rows). In both the $6 \times$ and $25 \times$ magnifications of sections (middle and lower pictures) we

changes induced after treatment with antiosteoporosis drugs, which appear to influence bone formation. In vertebrates, the hip joint is the main connection point between the lower extremity and the trunk. Therefore, all
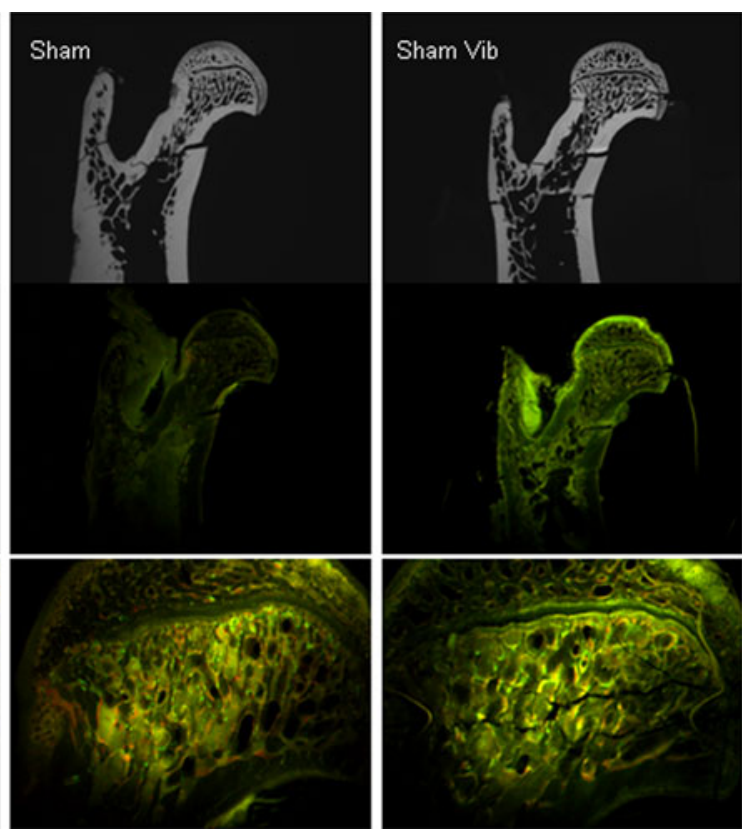

can see an increase of the intensity of fluorescence apposition in the trabecular area after vibration treatment (OVX-vib and sham-vib). Interestingly, as a side effect, a higher intensity of the fluorescence apposition was also seen in the small piece of the remaining muscle (insertion point) on the pick of the major trochanter in both vibrated groups

mechanical stimulations and movements of the trunk and lower extremity can influence the proximal femur. These properties, in addition to the known sufficient and thick muscle insertions (cuff) of the intertrochanteric region of 
the femur, make this skeletal site interesting for evaluating the effect of mechanical stimulations such as whole-body vibration. To study the antiosteoporotic effect of wholebody vibration in an animal model, it is better to use mechanical testing methods that more closely resemble clinical conditions; most osteoporotic hip fractures in humans result from lateral falls [7].

In our study, we tested the hypothesis that low-magnitude, high-frequency WBVV can improve biomechanical and histomorphometric properties of the proximal femoral bone.

The decision to use low-magnitude, high-frequency vibration in the present work was due to the results of experiments that showed that this form of mechanical stimulation can be more effective in comparison to lower frequencies [12]. Lastly, the most appropriate frequencies, durations, and amplitudes of vibration necessary for a positive effect are unknown, and the type of vibration signal is rarely reported [13].

After short-term WBVV, we observed an improvement in rat femoral strength with significantly higher values of maximal load $\left(F_{\max }\right)$ and stiffness in both OVX and sham animals. These results correlated with the results of the histomorphometric test. Not only the trabecular density but also the trabecular thickness (width) and the connectivity (trabecular node $/ \mathrm{mm}^{2}$ ) showed significantly higher values after the vibration treatment in both groups (OVX and sham). Our results confirm the antiosteoporotic effect of vibration treatment reported in the literature.

To determine whether the responsiveness of bone to low-magnitude, high-frequency parameters is modulated by endocrine imbalance, Judex et al. [10] applied different frequencies ( 90 and $45 \mathrm{~Hz}, 0.15 \mathrm{~g}$, each for $10 \mathrm{~min} /$ day) to the proximal tibia and distal metaphyseal femurs of OVX rats. After 28 days, the $90 \mathrm{~Hz}$-vibrated rats showed significantly greater bone formation (159\% higher in proximal tibia) compared to rats in the $45-\mathrm{Hz}$ group. Bone morphology in $90-\mathrm{Hz}$ animals indicated significantly higher trabecular bone volume and thicker trabeculae in comparison to distal femur in either controls or $45-\mathrm{Hz}$ rats [10]. Notably, the length of therapy may have a strong influence on the end results. Oxlund et al. [14] reported that 90 days of daily vibration treatment with $45 \mathrm{~Hz}(3.0 \mathrm{~g})$ for $30 \mathrm{~min}$ is able to significantly inhibit the decline in maximum bending stress and compressive stress induced by OVX in the rat distal metaphyseal femur and proximal tibia. In contrast to these positive results, Torvinen et al. [15] did not find any effects after a daily 4-minute vibration program in young adults. One of the reasons for these negative results, however, may be the relatively short duration of treatment [11].

In our study, a comparison between the weight of femurs before and after ashing confirmed the results of the biomechanical and histomorphometric tests. After treatment with WBVV, the mineral content of femurs in OVX rats reached approximately the level of the sham animals. In 1998, Flieger et al. [16] used vibration therapy $(50 \mathrm{~Hz}$, $2 \mathrm{~g}$ ) in an animal model for the first time. They found that vibration treatment can be used to inhibit the decrease of bone mineral content caused by OVX in rat. Ruan et al. [1] showed in their study that vibration therapy $(30 \mathrm{~Hz}$ and $5 \mathrm{~mm}$ amplitude) appeared to be useful in reducing chronic back pain and increasing the femoral neck and lumbar bone mineral density (BMD) in postmenopausal women with osteoporosis. The same authors observed improvement of BMD 6 months after the initiation of therapy.

One of the controversial issues is the effect of WBVV on cortical bone. In our experiment we observed an increase in the rate of bone formation after WBVV, mainly in the periosteal site of femoral cross sections of the subtrochanteric region, although the results were statistically not significant. Sehmisch et al. [11] showed weak improvement of cortical bone density in rat lumbar vertebrae after WBVV. Rubinacci et al. [17] also observed an anabolic effect of WBVV on the cortical surface. Rubinacci et al. [17] showed after WBVV under $30 \mathrm{~Hz}$ and $3 \mathrm{~g}$ conditions an increase not only in periosteal but also in the endosteal sites of rat tibias. In their opinion, the osteogenic potential of WBVV is limited to modeling of the bone cortex and depends on the amplitude of the vibration; OVX sensitizes rat cortical bone to whole-body vibration [17]. Under the conditions used in our study, endosteal bone formation remained nonsignificant after the vibration.

In our opinion, the questions related to which frequency and which amplitude afford the best results remain open. It is also important to mention that in our study we investigated only one frequency and amplitude. Further limitations of our work are the lack of tests on males, lack of tests on other skeletal sites, and the fact that only one direction of vibration (vertical) was tested.

\section{Conclusion}

Our results provide a structural basis for the recent reports that WBVV seems to be an osteogenic nonpharmacological treatment that increases bone strength. Our findings indicate that low-magnitude, high-frequency WBVV improves the trabecular microarchitecture of the proximal femur of rats. However, further experiments are needed to determine whether such mechanical stimulation is also able to prevent trochanteric fractures.

Open Access This article is distributed under the terms of the Creative Commons Attribution Noncommercial License which 
permits any noncommercial use, distribution, and reproduction in any medium, provided the original author(s) and source are credited.

\section{References}

1. Ruan XY, Jin FY, Liu YL, Peng ZL, Sun YG (2008) Effects of vibration therapy on bone mineral density in postmenopausal women with osteoporosis. Chin Med J (Engl) 121:1155-1158

2. Liu Y, Zhou J, Ye CQ, Bai GC (2008) Osteogenetic effect of mechanical vibration on bone [in Chinese]. Zhongguo Gu Shang $21: 400-402$

3. Gusi N, Raimundo A, Leal A (2006) Low-frequency vibratory exercise reduces the risk of bone fracture more than walking: a randomized controlled trial. BMC Musculoskelet Disord 7:92

4. Garman R, Gaudette G, Donahue LR, Rubin C, Judex S (2007) Low-level accelerations applied in the absence of weight bearing can enhance trabecular bone formation. J Orthop Res 25:732-740

5. Ishihara A, Sasaki T, Debari K, Furuya R, Kawawa T, Ramamurthy NS, Golub LM (1999) Effects of ovariectomy on bone morphology in maxillae of mature rats. J Electron Microsc (Tokyo) 48:465-469

6. Bagi CM, Wilkie D, Georgelos K, Williams D, Bertolini D (1997) Morphological and structural characteristics of the proximal femur in human and rat. Bone 21:261-267

7. Tezval M, Stuermer EK, Sehmisch S, Rack T, Stary A, Stebener M, Konietschke F, Stuermer KM (2010) Improvement of trochanteric bone quality in an osteoporosis model after short-term treatment with parathyroid hormone: a new mechanical test for trochanteric region of rat femur. Osteoporos Int 21(2):251-261

8. Stuermer EK, Seidlova-Wuttke D, Sehmisch S, Rack T, Wille J, Frosch KH, Wuttke W, Stuermer KM (2006) Standardized bending and breaking test for the normal and osteoporotic metaphyseal tibias of the rat: effect of estradiol, testosterone, and raloxifene. J Bone Miner Res 21:89-96
9. Biering-Sorensen F, Hansen B, Lee BS (2009) Nonpharmacological treatment and prevention of bone loss after spinal cord injury: a systematic review. Spinal Cord 47:508-518

10. Judex S, Lei X, Han D, Rubin C (2007) Low-magnitude mechanical signals that stimulate bone formation in the ovariectomized rat are dependent on the applied frequency but not on the strain magnitude. J Biomech 40:1333-1339

11. Sehmisch S, Galal R, Kolios L, Tezval M, Dullin C, Zimmer S, Stuermer KM, Stuermer EK (2009) Effects of low-magnitude, high-frequency mechanical stimulation in the rat osteopenia model. Osteoporos Int 20(12):1999-2008

12. Aleyaasin M, Harrigan JJ (2008) Vibration exercise for treatment of osteoporosis: a theoretical model. Proc Inst Mech Eng [H] 222:1161-1166

13. Prisby RD, Lafage-Proust MH, Malaval L, Belli A, Vico L (2008) Effects of whole body vibration on the skeleton and other organ systems in man and animal models: what we know and what we need to know. Ageing Res Rev 7:319-329

14. Oxlund BS, Ortoft G, Andreassen TT, Oxlund H (2003) Lowintensity, high-frequency vibration appears to prevent the decrease in strength of the femur and tibia associated with ovariectomy of adult rats. Bone 32:69-77

15. Torvinen S, Kannus P, Sievanen H, Jarvinen TA, Pasanen M, Kontulainen S, Nenonen A, Jarvinen TL, Paakkala T, Jarvinen M, Vuori I (2003) Effect of 8-month vertical whole body vibration on bone, muscle performance, and body balance: a randomized controlled study. J Bone Miner Res 18:876-884

16. Flieger J, Karachalios T, Khaldi L, Raptou P, Lyritis G (1998) Mechanical stimulation in the form of vibration prevents postmenopausal bone loss in ovariectomized rats. Calcif Tissue Int 63:510-514

17. Rubinacci A, Marenzana M, Cavani F, Colasante F, Villa I, Willnecker J, Moro GL, Spreafico LP, Ferretti M, Guidobono F, Marotti G (2008) Ovariectomy sensitizes rat cortical bone to whole-body vibration. Calcif Tissue Int 82:316-323 